\title{
Value Chain Analysis as a Catalyst in Gender Main Streaming
}

\author{
Sanni T. Adebayo \\ Department of Social Work and Social Administration, Kabale University, Uganda
}

Copyright $\subseteq 2016$ by authors, all rights reserved. Authors agree that this article remains permanently open access under the terms of the Creative Commons Attribution License 4.0 International License

\begin{abstract}
This article examines the value chain analysis as a catalyst in gender mainstreaming. Gender activities in the global world have revealed that, one sex has been marginalized by the other. From time immemorial, gender roles and activities differ, some base on physical ability and so on. This aimed at transforming mainstream policies by introducing a value chain analysis in a gender equality perspective. However, it has been largely used as an alibi for neutralizing the negative action in gender mainstreaming. The policy of gender mainstreaming incorporating gender sensitive aspects into external and internal policies and practices has been widely adopted throughout the international development community since the world conference on women in Beijing in 1995. Women are statistically the global majority; women cannot be treated as "a special case" but their needs and interests must be protected as integral part of any development policy as those of men. The paper gives an insight of the importance of a value chain analysis in gender mainstreaming.
\end{abstract}

Keywords Gender Mainstreaming, Value Chain, Catalyst, Marginalized

\section{Introduction}

A value chain is the whole series of activities that create and build value at every step of production. According to Porter (1) defines the value chain as made of primary activities and support activities. Primary involves inbound logistics (getting the material in for adding value by processing it), operations (which are all the processes within the manufacturing), outbound (which involves distribution to the points of sale), marketing and sales (which go sell it, brand it and promote it) and service (which maintains the functionality of the product, post sales). The relative status of men and women; the interaction between gender and race, class and ethnicity and questions of rights, control, ownership, power and voice all have a critical impact on the success and sustainability of every development intervention.

'Gender refers to the socially constructed rather than biologically determined roles of men and women as well as the relationships between them in a given society at a specific time and place. These roles and relationships are not fixed, but can and do change. 'Gender mainstreaming' was defined by the United Nations Economic and Social council in (6) as 'a strategy for mainstream women's as well as men's concerns and experiences an integral dimension of the design, implementation, monitoring and evaluation of the policies and programmes in all political, economic and societal spheres so that women and men benefit equally and inequality is not perpetuated'.

In practice, gender mainstreaming means identifying gap among men and women; and bridge them to result in gender equality. Despite good intentions and some real progress, the development community, other stakeholders included, is still falling short in delivering on its promises. Many of the problem areas were identified in the UN Secretary-General's Review and Appraisal of the Implementation of the Beijing Platform for Action. These areas include the development of accountability mechanisms; allocation of sufficient resources; attention to gender equality; targeting not just 'soft' areas for gender mainstreaming (such as health and education), but also supposedly 'gender-neutral' areas, such as infrastructure development and economic policies; and strong political commitment and will.

\section{Review of related Concepts}

Gender inequality has affected the world at large. However, its impact is felt more in Africa. Gender equality and the empowerment of women have long been considered as moral and legal issues. More recently these issues have taken on a very different connotation mainly in terms of economic efficiency. In fact gender imbalances affect economic efficiency with regard to the allocation of resources as well as the enhancement of productivity for sustainable development African Statistical Journal (6). 
There is universal recognition that gender equality and women's empowerment are necessary conditions to achieve sustainable development, as supported by evidence in several in studies. Cross country analysis conducted by Klasen (1) suggest that if countries in the Middle East, Africa and South Asia had closed their gender gaps in years of schooling at a rate achieved by East Asian countries from 1962-1990, the GDP in these countries could have grown by one half percentage per year. Udry et al (3) mention that the value of household output in Agricultural production in Burkina Faso would benefit from an increase of $10-20 \%$ by shifting existing resources between men and women's plots within the same household. They also noted that if the government gave the same level of agricultural inputs and education to women, the yields obtained by women could increase by more than $20 \%$. Baliamoune (1) shows that higher integration in world markets and growth causes gender inequality in Sub- Saharan African countries.

The term gender mainstreaming may be conceptualized in two different ways: on the one hand it is an integrationist strategy which implies that gender issues are addressed within the existing development policy, strategies and priorities. Hence, throughout a project cycle, gender concerns are integrated where applicable. On the other hand, mainstreaming also means agenda - setting, which implies the transformation of existing development agenda using a gendered perspective. These two concepts are not exclusive and actually work best in combination.

Value Chains in gender analysis conceptualize enterprises and economic activities, not as separate discrete units or functions, but as part of chains, holistic networks and systems of different linked production and exchange activities operating in different geographical areas: local, national and international.

The value chain describes the full range of activities that are required to bring a product or service from conception, through the different phases of production(involving a combination of physical transformation and the input of various producer services), delivery to final consumers, and final disposal after use, Kaplinsky and Morris (2 p4).

Value chain is a sequence of target-oriented combinations of production factors that create a marketable product or service from conception to the final consumption. This includes activities such as design, production, marketing, distribution and support services to the final consumer. The activities that comprise the value chain can be contained within a single firm or divided among different firms, as well as within a single geographical location or spread over wider areas. The term Value Chain refers to the fact that value is added to preliminary products through the combination of other resources, ILO (6).

\section{Socio-cultural and Economic Explanation of Gender Differences}

Gender explanations of differences and inequalities in terms of biology need to be constantly questioned and explained. Gender differences in participation, pay and conditions at different parts of the value chain are often explained in term of 'women's innate characteristics' like docility, patience to do repetitive work or lack of physical strength.

However, biological sex differences are inadequate and misleading explanations of engendered divisions of labour. For instance in some culture, most work are regarded as male work, while some are regarded as female work. In Ethiopia, weaving is seen as a male activity, and women are seen as too weak to operate a traditional loom. While in Kenya, however, traditional weaving is generally a female activity. Equally importantly, sex differences do not explain gender inequality, or devaluing of women's skills. There is question to be asked in Value Chain Analysis why these characteristics are undervalued. Why work is not arranged in such a way as to facilitate women's participation. For example: female-friendly technology and family-friendly working hours.

Any justification of gender inequalities in terms of 'culture' and 'tradition' can be challenged in value chain development. Gender inequalities exist in all cultures - in both industrialized and low income countries. Many dimensions of 'culture' and tradition' are constantly changing. Supporting perpetuation of gender inequalities on the grounds of 'cultural sensitivity' is no more justified than perpetuation of the equally 'cultural' discrimination on the basis of race and ethnicity, religion, caste or disability.

There is often confusion because of the assertion that 'gender means women and men'. All the indicators of human development in most countries show that women are significantly disadvantage women, and a focus on women's needs and interests. The focus on 'gender policies' rather than 'women's projects' came about because it was realized that removing gender inequalities which disadvantage women requires changes not only in women's behaviour and position, but also that of men. It also requires change in underlying gender inequalities in power and resources that structure the ways in which women and men behave towards each other. Addressing gender inequalities therefore generally requires not only strategies targeting women, but mainstreaming change in gender relations in strategies targeting men, for example: the inclusion of gender awareness in livelihoods training for men as well as women.

Gender equality of opportunity is, however, often insufficient for gender equity. Gender equality of opportunity often requires significant changes in institutional culture and processes - including language, assumptions, relationships and incentives. Many countries have legislation and even traditional religious law against different forms of discrimination- for example: property rights legislation, which remains unimplemented without supportive measures to enable women to take advantage of these laws. There is often a need for an initial period of affirmative action in order to support sufficient numbers of 
women to challenge existing inequalities and stereotypes and to establish new norms and practices that give equality of opportunity.

It is only when women have equality of opportunity backed by supportive policies to enable them to realize those opportunities that different outcomes between women and men can be judged to be equitable. For example, women choosing to stay at home rather than work, or to do certain types of job. Ultimately, gender equality will involve not only increasing women's access to profitable economic activities, but changing the nature of relative responsibilities. In a gender equitable society, women and men may continue to make different choices, but gender biases cease to influence those choices.

It is important to bear in mind that women are not a homogeneous category, any more than men are. There must be space within the process for all women to come together to discuss and address their common gender needs. It is not therefore sufficient to include a few women as one 'stakeholder group', but women must be included across stakeholder categories.

\section{Challenges in Gender Differences - Roles and Activities}

Gender differences in roles and activities are very crucial in gender mainstreaming. Another issue is the problem-ridden conceptualization of women's and men's work in rural environments and, in particular, the failure (by census-takers and researchers who are not gender-aware, for example) to recognize the importance of their differing roles. Analysis of the gender division of labour has revealed that women typically take on three types of roles in terms of the paid and unpaid labour they undertake, Razavi and Miller, (2). These three roles can be described as follows:

1. the productive role: this refers to market production and home/subsistence production undertaken by women, which generates an income (whether financial or 'in kind'),

2. the reproductive role: this refers to the child-bearing and child rearing responsibilities borne by women( which are essential to the reproduction of the workforce; and

3. the community management role: this refers to activities undertaken by women to ensure the provision of resources at the community level, as an extension of their reproductive role, Razavi and Miller, (2).

An understanding of these three roles can inform gender-aware planning that takes into account the differential impact of programmes and projects on women and men because of women's triple role. When under-estimations and under-valuations of rural women's work are found, as they so often are, in the sphere of development planning, the consequences are serious.
Failure to acknowledge the importance of women's multiple contributions to rural survival means that practical policy interventions are frequently detrimental both to women themselves and to their communities.

Another factor that needs to be taken into account tasks, activities or enterprises may be regarded as 'male' or 'female'. For example, women typically gather forest products for fuel, food for the family, fodder for livestock and medicinal uses. Men more often cut wood to sell or use as building materials. In order to secure sustainable and equitable management of forest resources, therefore, both women and men need to be consulted in the design and implementation of forestry projects. Similarly, where livestock is concerned, women and men often own different animal species and use different animal products, and any policies or programmes would need to address the needs of both, World Bank (6).

\section{Value Chain Development in Gender Mainstreaming}

Value Chain Development involved some sort of stakeholder participation. However, all involve stakeholder participation in the sense of finding out information from stakeholders. This result in pull-up and push-up explain bellow:

In 'pull-up' Value Chain Developments, the focus has generally been on 'key stakeholders' defined as leaders of industries and policy-makers who are seen as having the best overview and knowledge of the chains concerned. Generally other stakeholders are added, for example relevant development agencies, government officials, maybe union leaders, perhaps even leaders of women's associations. The involvement of more vulnerable stakeholders is often seen as too controversial, costly and difficult - often, even if they are organized.

In 'push-up' processes, the focus has often been very explicitly on consulting with and organizing people at or near the bottom of the power hierarchies in the chain, and then negotiating upwards. Generally some form of participatory methodology and tools are used which include these people in research and/or planning, this is then linked to an advocacy process. With 'push up' processes there may well be difficulties linking with those who have an economic overview for the chain as a whole, and hence then main drivers of change. Although it may be possible to establish short-term gains, these gains can be undermined by macro-level changes in the long-term unless there has also been a thorough analysis of these.

Gender Value Chain Action Learning (GEVCAL) aims to bridge the 'pull-up' and 'push-up' approaches to Value Chain Development (VCD). It does, however build most on the 'push-up' approaches that threat conflict of interest as something to be negotiated rather than avoided or ignored. In GEVCAL, participation is an inherent part of the definition of pro-poor development. This includes stakeholder input into: 
1. Design of the process in order to increase commitment and widen the range of skills and experiences from the start to maximize the relevance and contribution to pro-poor development.

2. Research and analysis to build stakeholder capacity for their own research and analysis and promote communication, understanding and respect between stakeholders at different levels.

3. Deciding the action strategy.

4. Implementation and monitoring of Value Chain Development strategies at individual, enterprise, institutional and policy levels.

However, the aim of participation is not participation per se, therefore are circumstances where extensive participation of all stakeholders is neither possible in terms of political context or resources, nor desirable in terms of either empowerment of the most vulnerable, or reliability of the information and hence generating the most useful pro-poor recommendations. Very poor people like everyone else, and often more so, have many claims on their time, resources and energy. They have much to lose from badly designed policies and processes and/or where making their voices publicly known may have adverse repercussions. Even if it is their interests which are to be clearly prioritized, it is important to ensure that their precious time, resources and energy are clearly focused on those issues and areas where their participation is most likely to lead to realizable benefits for them. As far as possible, people should benefit directly from the time and energy they give to the research process itself, in terms of learning, understanding and capacity-building, and not treated as unpaid data givers of information extracted by outsiders.

\section{Conclusions}

Gender mainstreaming is the area whereby the activities include economic, political, social and other areas be taken into consideration by government and stakeholders, for the virtues of development. In this context it is not the gender dimension which is critical but the new models which emerge have gender embedded in them from the beginning. The older paradigms have proven unsustainable and governments are searching for new approaches which will be cost effective, be less centralized, involve a range of partners in development, tackle the mounting problem of rural poverty, avoid environmental damage and meet the demands for more participation by the end- users. This is a daunting challenge and it needs the skills of administrators, the patience and support of donors, political will and leadership and a willingness by communities to play an active role.

\section{REFERENCES}

[1] Baliamoune-Lutz M. Gender Inequality and Growth in Sub-Saharan Africa and Arab Countries," ICER Working Papers 25-2007, ICER- International Center for Economic Research.

[2] Barnes, J, Kaplinsky, J, Morris M. Industrial Policy in developing" Economies: Developing dynamic comparative advantage in the South African; 2004.

[3] Klasen, S. Does Gender Inequality Reduce Growth and Development? Evidence from Cross-Country Regressions Policy Research Report on Gender and Development. Working Paper Series No. 7; 1999.

[4] Porter, M.. "Competitive Strategy: Techniques for Analysing Industries and Competitors", Free Press, New York; 1980.

[5] Mayoux, L. "Empowering Enquiry: A New Approach to Investigation. 2003 [cited 2010] From $\mathrm{http}: / /$ www.enterprise-impact.org.uk/informationresources/t oolbox/empoweringenquiry.shtml.

[6] Mayoux, L, Anandi.(2005): "Participatory Action Learning in Practice: Experience of Anandi, India." Journal of International Development, 17, 2005[cited 2010] fromhttp:///www.enterprise-impact.org.uk/informationresour ces/Toolbox/PALinpractice.shtml.

[7] Mccormick, D, Schmitz, H. Manual for Value Chain Research on Homeworkers in the Garment Industry. Nairobi and Brighton, Institutes for Development Studies, University of Nairobi and University of Sussex; 2001.

[8] Herr, M. An operational guide to Local Value Chain Development ILO, Geneva; 2007.

[9] Razavi, S, Miller, C. (1997): Conceptual Framework for Gender Analysis within the Development Context. New York: UNDP Gender in Development Programme; 1997.

[10] Tallontire, A., Dolan, C., Smith, S, Barrientos, S. "Reaching the Marginalized? Gender, Value Chains and Ethical Trade in African Horticulture." Development in Practice; 2005.

[11] Udry, C., Hoddinat, J., Alderman, H, Haddad, L. 'Gender Differential On Farm Productivity: Implications of Household Efficiency and Agricultural Policy; 1995. 20,: 407-423.

[12] Velugu. "Gendered Value Chain Analysis: Red gram, Groundnut, Neem, and Tamarind.” 2007 [cited in 2010] Fromhttp://www.velugu.org/downloads/gender.pdf.

[13] Veneklasen, L. Miller, V. A New Weave of Power, People and Politics: The action Guide for Advocacy and Citizen Participation. Oklahoma, World Neighbours; 2002.

[14] Veneklasen, L. Miller, V. The 1995 Commonwealth Plan of Action on Gender and Development. London: Commonwealth Secretariat; 1995.

[15] Veneklasen, L, Miller, V. Gender Mainstreaming in Education: A Reference Manual for Governments and Other Stakeholders. London: Commonwealth Secretariat; 1999. 